Proceedings of the 2012 Winter Simulation Conference

C. Laroque, J. Himmelspach, R. Pasupathy, O. Rose, and A.M. Uhrmacher, eds

\title{
EVALUATION OF METHODS USED FOR LIFE-CYCLE ASSESSMENTS IN DISCRETE EVENT SIMULATION
}

\author{
Jon Andersson \\ Anders Skoogh \\ Björn Johansson \\ Product and Production Development \\ Chalmers University of Technology \\ SE 41296 Gothenburg, Sweden
}

\begin{abstract}
The incitements from society for life-cycle assessment (LCA) and credible ecolables are ever-increasing and often important for successful marketing of products. Robust assessment methods are important for comparable, useful and trustworthy LCAs and ecolables. In order to improve the metrics of a product's ecolable, is it important to fully understand its production system. Discrete Event Simulation (DES) models are able to provide more detailed information than traditional LCA approaches. Therefore, methods used to combining LCA in DES have been developed during the last decade. The combined approaches have matured and the experiences grown. This article compares six previous cases and aims to summarize and discuss their experiences to aid future development. The results show where it is specifically important to make good decisions throughout the modeling methodology, for example goal and scope definition, trustworthy input data for sensitive parts, and communicable impact categories.
\end{abstract}

\section{INTRODUCTION}

The application of Discrete Event Simulation (DES) in sustainability analyses of production systems has been increasingly popular and important during the last decade. Especially the combination of DES with data and analysis techniques originating from Life Cycle Assessment (LCA) has been developed and evaluated in evaluation and development of production systems. In recent research, this combined approach (DES and LCA) has also been evaluated with regard to its feasibility for environmental product assessment, e.g. ecolabeling (Andersson et al. 2011).

A substantial part of the research and development within the area has focused on state-of-the-art analyses and descriptions of how to use DES to reducing the energy consumption in production (Seow and Rahimifard 2011) (Thiede et al. 2011) (Solding et al. 2009). Others have used the DES-LCA combination in a more holistic approach, for example by performing emission simulations together with Level of Automation (LOA) and ergonomic analyses (Lind et al. 2008). Using DES for detailed LCA was done by Löfgren and Tillman (2011) a case in the manufacturing industry case. In other words, the development has been going on for some time, accumulating ideas and solutions from a wide range of application areas and companies. However, few studies have collected these experiences in order to describe bestpractice procedures and to make sure that the knowledge gained can be perceived and sustained.

This paper aims to compile the lessons learned from previously performed and documented environmental impact assessment using DES. These experiences will result in a list of common problems, ideas, and recommendations important to address in future research and development. Documentation from six real-world case studies from three different research projects will be analyzed and complemented with interviews with project team members. Three of the included case studies are performed in a research pro- 
ject called REELIV, one comes from a project called SIMTER (Lind et al. 2009), and the two remaining are performed in a current research project named EcoProIT (Andersson et al. 2012). The most important experiences are summarized and discussed. The paper aims to provide experiences that give future methodology development and applied cases a better base for success.

\section{METHOD}

The aim of the paper is to summarize current experiences from environmental impact assessment in DES. The chosen approach is to gather and compile information from multiple, previously performed and documented case studies. The cases have all been performed from year 2007 and forward.

The reports and working papers from these cases serve as a basis for the collected experiences. The reports are first reviewed individually to identify important sections, e.g. the analysts' experiences, review comments, and analyze parts with a major difference from the other cases. The important sections are then compared and analyzed in consideration to the result of the cases; see section 4. To fill possible gaps, the reports are complemented by structured and open interviews with project members.

The cases were chosen from three projects: REELIV, SIMTER, and EcoProIT. REELIV was an early research project with the aim to evaluate whether it is possible to combine LCA with DES. SIMTER (Lind et al. 2008) took the idea one step further and used DES for LCA analysis in parallel with LOA and ergonomic assessments. EcoProIT (Andersson et al. 2012) is a current project aiming to develop methods and a tool for standardized environmental assessments in DES. The major motivation to use these projects is that the participating analysts in the project cases are available for interviews with the authors of this paper. Other cases exists, however the reports of the cases do not always comply with the aim of this paper. Contacts with involved personal were viable for those cases. Other cases that not were directly used in this review are presented in the introduction.

The three cases in the REELIV project are all performed in the food industry. One case is chosen from the SIMTER project. This case studies both ergonomics, LOA and LCA at a manufacturing site. Two cases from the EcoProIT project are chosen. They focus on accounting ecolabel assessment for the production of one product.

First part of the paper presents the cases shortly and explains important approaches and experiences from the case. The second part summarizes all the experiences and creates a list of how different approaches affect the result of the analyses. The last part discusses the experiences and gives advice for further practice and development.

\section{CASES}

The cases are analyzed and compared against each other. The most significant differences is highlighted and discussed. The areas of specific interest for the analysis are:

- Scope and goal definition.

$\circ$ The problem definition is compared with the actual results.

- The functional unit definition is analyzed for relevance.

$\circ$ The purpose of the study is analyzed.

- The overall method used is analyzed.

- Verification and validation processes used are analyzed.

- The used impact categories or environmental result variables and how they impact the result.

(A functional unit is the unit that the study uses to count the environmental impact to, e.g. one product produced, $10 \mathrm{~kg}$ of product produced or the production plant)

\subsection{Case Apple Juice}

The case (Persson and Karlsson 2007) is a study of an apple drink production line. The production line produced many variants of apple juices but all products basically used the same set of processes. 
The main purpose of the case study was to measure the most efficient batch size for the production line, both in regards to economic cost and environmental impacts. However, during the project additional scenarios and questions were added. The additional questions were analyzed using the same model, but requiring minor changes for the additional scenarios. The original model should therefore need to be flexible to enable changes for other analyses.

The functional unit for the case study is set to the product mass of one $\mathrm{kg}$. A liquid product could promote the use of volume as functional unit. However, the different product variants in the study all have a density very similar to water. Furthermore, many of the ingredients are also measured by weight.

The problem formulation is very broad and enables lots of room interpretation. As a result, it is not possible to trustfully judge if the results of the project fully answers what is asked. There are nice answers for the larger part of the problem. However, the project lack specific results and cannot be said to answer everything in the problem definition.

The Method used during the project equals an extended version of Banks model (Banks and Nelson 2010). The method used here is essentially extended with processes for LCA steps. The resulting method is very extensive and detailed, while promoting a structured work progress. There are loopbacks for the experiment or scenario creation process which promotes building a flexible model from the start to enable the creation of additional scenarios later in the project.

The model was validated against historical production rates and using face validation. Hence, the process part of the model was validated using good practice. The results of the validation were not completely positive; this was taken into account when using the result from the model.

Validation of the environmental parts of the results do only considered waste and were performed using historical data. The results could not be fully validated, which was taken into account in the analysis of the results. No validation was performed for the output of used consumables or resulting emissions.

There is no clearly defined impact category used for the comparison analyzes. The results that are used in the analysis are consumables, i.e. used water and energy used in processes. To analyze the model are also wasted products and emissions from used raw material used.

The main problem facing the model builder was to estimate the amount of waste produced by the system. From the company's' side there was very little data collected on waste products. The analyst had to estimate and calculate backwards from input-output relations to get the data. Moreover, there were major problems with the environmental data and it cannot be fully trusted.

This and all the other REELIV does not cover emissions from the facilities.

\subsection{Case Cultured Dairy Products}

This case (Alvemark and Persson 2007) studies a production system producing different types of cultured dairy products in three parallel flows. The system involves highly automated equipment but requires a lot of human control and interaction. The production flow is complex and major generalizations for the production planning were inevitable.

The goal and scope is focused on model creation rather than environmental analyses. However, the project also presents a couple of scenarios to be tested, analyzed, and compared. The goal is therefore to create a flexible model for analysis of different scenarios. This enables scenario design at later stages on the project timeline. Hence, more knowledge is gained about the production system before the scenarios are built.

The functional unit for the model is mass, one hundred $\mathrm{kg}$ of product. This is convenient compared to using volume as the functional unit since the company historically measured their production and output in kilograms. The unit supports communication of the results to stakeholders at the company and facilitates usage and conversion of input data.

The method used in the project is developed in the REELIV project. It is very much focused on the LCA part of the project. The project definition is explained in detail, however the implementation, validation and analyze phases are not given much room. The lack of focus on the validation part highlights the lack of validation for the project. Only face validation for the production flow is performed. No validation 
of the environmental output such as assessing the usage of consumables or measure emissions is performed.

The outputs of the model are consumables and energy in forms of oil, electricity, water and some toxic resources. Those were used as different ways to compare the processes and to analyze the different scenarios. It is sometimes hard for the reader to compare different consumables to each other. For some parts of the analysis, different outputs are aggregated to the impact category $\mathrm{CO} 2$ equivalents. This part is easier to understand for the reader. However, this is not preformed throughout the report, which makes some parts harder to follow.

The major issue in this project was that it took a lot of time to build a robust model. The analyst would have liked to add more time on modeling and data collection. However, the model was detailed enough for the conclusions that are stated in the result which to a general extent answers what is asked within the goal and scope of the project.

\subsection{Case Meat Products}

The case (Ingvarsson and Johansson 2006) studied a sausage production line. It was the first of three Master's thesis works within the project REELIV. Therefore no previous experience existed to support the case. The problem formulation focused on efficiency parameters and not on environmental impact assessments.

The goal and scope for the project was to analyze the production line from both production efficiency and an environmental point of view. However, the project ends up focusing more on bottlenecks and economic analyses then on environmental assessment. The lack of focus on the environmental part in the analysis reduces the suitability to use the results to draw any major conclusions. However, seen as a complement to the main analysis the environmental part is still useful as an expansion of the results.

The sausage mass (kg sausages) is used as the functional unit. Individual sausages have different weight. A functional unit of mass makes it possible to compare different types of sausages.

Impact categories are not used. The output includes energy and meat consumption. No declaration of the actual environmental impact such as emissions is given. However, meat consumption is converted to energy to give an overall value. The energy used is aggregated and analyzed per production part. However, the results are more an outcome from the data collection rather than affected by dynamic aspects from the model.

The project is only cover LCI (life-cycle inventory) information for meat production and the energy consumption in the processes. This system boundary excludes buildings, other raw material to the sausages and other supporting function that enables the production. This system boundary is used based on the assumption that the meat production is the most important environmental impact.

The method used is the banks model with an additional part of data collection for consumables used. The method gives no or little support for structured environmental impact assessment. Hence, the result is very much focused on the economical perspective.

The model is validated from historical data. Thus, only the process part of the model is validated. The environmental part is not validated.

\subsection{Case Automotive Industry}

The aim of the project was to create a simulation model from were a couple of analyses in ergonomic and environmental aspects. The ergonomic aspects was important for the case which lower the model specialization for environmental impact assessments. The technical system boundary for the project is only considering a small part of the production. However the analyze in this part is detailed.

The project used and evaluated a tool developed in the SIMTER project. The tool is a plug-in to a discrete event simulation software program. All calculation are preformed based on the process times and LCI data for the consumables. 


\section{Andersson, Skoogh and Johansson}

The goal and scope for the LCA part is not very clearly defined. The project is focused on the evaluation of the tool and therefore not focused on the actual analyze results.

As the functional unit they used the total production part per year. The unit is very brief and has to be coupled to the total output and usage of the plant. For the functional unit they only measured energy consumptions for the used machines and forklifts in the model. The impact from building and supporting resources is not evaluated. Likewise, no other consumables then energy is accounted for.

The base model was compared to another more automated scenario. The problem for the new scenario was to get information for consumption of the new scenario. All energy consumptions for the model were collected from the equipment provider. The information from equipment provider is very general and not dependent on the product being processed. The result from the analyses is not validated and could be hard to use in a large extent for decision making.

\subsection{Case Fork Lift Part}

The project (Lindskog et al. 2011) analyzed manufacturing production plant creating lots of different parts for different costumers. The main project goal for is to analyze the environmental assessment of the functional unit one sub part to a fork lift. Secondary goals were to evaluate and suggest a method for environmental assessments in DES. Including to propose result indicators and important input data.

The method used was developing during the project. Important part of the method is the structured data collection part. The different categories came with explanations and questions to ask for to determine how and where to find the data and information.

The project also had a major discussion of allocation problem of overhead impacts e.g. building emission. The overhead impacts had to be allocated to different products produced in the facility. The project tested five different allocation methods to be aware of the how the choice would impact the results. ISO 14040 rank the allocation methods to first avoid allocation by system expansion, then to use physical parameters as a method and last to use economical parameters. The allocation methods used in this project used physical values though a system expansion in the very diverse manufacturing company makes system expansion impossible. In this case storage space was the best method for allocation of building emissions, but for some emissions delivery method was used.

The output for the environmental analyses is Acidification potential (AP) and GWP. AP and GWP was easy to communicate to costumer and by the decisions maker.

As verification process for the base model a static LCA was developed in parallel. This enables good verification of the environmental result against another study performed by another practitioner using the same input data.

The model was validated using historical data. But only the process could be validated.

\subsection{Case Steel Cans}

The goal and scope section defines that the steel cans GWP impact shall be measured. It states that a DES simulation model will be used for the analyses. The model should also enable reuse for other environmental impact for expanded use later.

The method used is a development of the method used in the fork lift part case. The cases have the same accounting goal.

The process parts energy use where measured individually where it was possible. Electricity for the individual process part was measured in detailed. However, used pressured air was harder to measure in detail. The centralized air compressor is used for the hole production facility and had to be allocated. For allocation the historical production rate between the other produced products was used. It was assumed that all different products used same amount of air per can.

The simulation model is developed in multiple levels for the environmental impact calculation. For each steel can, the simulation model track process times and time in the production parts and facility. The output of the steel cans process times and extra consumptions from processes is send to an external calcu- 


\section{Andersson, Skoogh and Johansson}

lation sheet and calculated to consumables for the processes, e.g. one minute direct use of a machine is converted to the amount of energy used by the process in that minute plus additional used consumables. The consumables are then in third step converted to emissions from static LCI tables for respective consumable.

Overall emission, i.e. buildings, standby time for processes and other support functions, is allocated primary to the products depending on for how long they stayed in the building, or evenly to all products that used the process that had standby emissions. The model is validated against historical data. However, no validation is preformed of the environmental impact results more than an internal review process. Verification is however performed by basic code checking and by summing all end resulting consumables and check against what should have been used.

\section{SUMMARISE EXPERIENCE}

The cases can be put on a time line with the accompanied project, and the experiences extracted from those cases. The experiences are to some extent transferred to the next process.

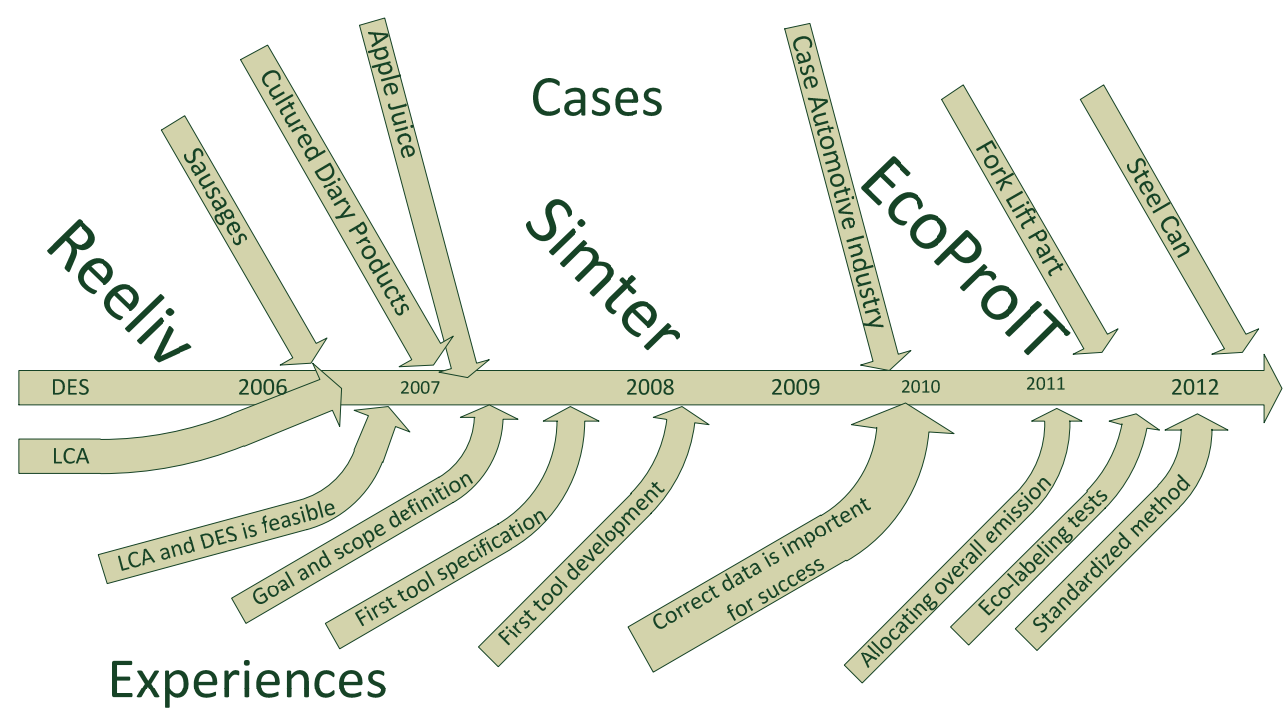

Figure 1 Experience time line

\subsection{Method}

Compared to normal simulation approach the LCA approach needs some addition. The projects setup an extra definition on why we want to do this and what to use the model for. Models used to test many scenarios should be adapted and focused on the difference between the scenarios. Models used for undefined scenarios would have to have a broader focus when defined scenarios should include high quality information of the scenarios differences. Models used for ecolabeling should take a broad system perspective and have a holistic lifecycle perspective.

The method for the approach must account for extensive data collections, validation and verification.

\subsection{Levels of aggregated equations}

To be able to manage the data and support verification of the environmental impact multiple levels of equation is important. Levels of equations refer to transparent result calculation model in where the total calculation is done as late as possible. Instead the emissions should be calculated on used consumables, which are calculated on lead times and process times. The output from the model is lead times for differ- 
ent part of the production for each product or functional unit (100g of sausages). From the process time the consumed consumables (energy, oil or steel) are calculated. From those consumables for each functional unit the emissions can be calculated from LCI databases.

The level of equations also enables useful sensitivity analyses on the equations. By analyzing the constants in the resulting equation significant spots for the model can be identified. Sensitive parts can then be subject for a more detailed analyze.

\subsection{Verification}

Verification of simulation models and calculations are important (Sargent 2010). In all the cases considered in this paper a part or all the environmental impact calculations are based on process outputs from simulation model. Therefor it is important that the model is fully verified before verifying the environmental calculations.

The first action is to internally review all equations and verify that they calculate what is supposed to. This demand well documented equations. Leveled equations where it is possible to sum total used consumables support effective verification.

The fork lift part case attempted to verify their code by preforming an external LCA based on the same input data. The method was resource extensive but give the modeler extra verification validity. Discussions with the modeler gave new inputs to both approaches.

\subsection{Validation}

To validate the process data all the cases used historically input and output methods. As for verification it is important to validate the simulation model before validating the environmental calculations. Hence, the environmental output is based on the process data in the model, ISO 14044:2006c (2006b).

The only practical method to validate an LCA is to use external reviewer. Likewise is it the only validation method when using discrete event simulation. However, much can be done to ensure quality. If the information is only used internally and for scenario comparability there will not be a need for more than a rigid verification process of the environmental impact calculations.

\subsection{Waste management}

There are two waste problems; the first is related to data management and LCI data. In the food industry cases the problem with the waste was to measure the amount of wasted food. The modeler performs many estimates which are hard to validate. Depending on how the wasted products are treated by the waste management system the LCI data changes a lot. Steel is highly recycled. The correct input data has to be used for the right waste management. In the food industry cases the problem with the waste was to measure the amount of wasted food. The modeler performs many estimates which are hard to validate.

The second is related to trashed products that already have accounted emissions. Those emissions have to be allocated to other products. In the food industry cases all emissions the wasted product was responsible for are allocated to the other product. The cases when batches were the cause of waste the wasted products emissions were allocated to the next batch. The steel can project had good data for wasted product. Emissions from trashed cans were allocated to the specific batch processed at the time.

\subsection{Input Data Management}

Major problems for all cases are to gather data. The problem with finding LCI data is connected with the lack of databases containing information representing all consumable. It mostly impossible to find LCI data that perfectly fits into the model. Assumptions and adoptions of existing dataset must be done to avoid extensive data collection. For the processes, process speeds, breakdowns repair times need to be collected in enough quality. Moreover, for the process the used consumable needs to be measured. To de- 
cide if correct quality is reached, a sensitivity analysis can show which data that need the most detailed data.

\subsubsection{Individual Process Electricity Measurements}

Most of the cases use own estimations or data from equipment suppliers. Such data will increase the uncertainty of the output data. In the cases with individual measurements for processes it is easier to distinguish the amount of energy used for actual processing compared to support functions (e.g. idling machines or building energy consumption). For manufacturing processes each state for the machine has to be collected (Skoogh et al. 2011) i.e. one static value for processing, one for idle, one for standby etc.

\subsection{Impact Categories}

All the early except the diary product projects primary assess energy use for the processes in the production. Use impact categories to highlight the actual problem with the emission for the product. The dairy product project sum the output in $\mathrm{CO}_{2}, \mathrm{SO}_{2}, \mathrm{NO}_{3}$, and ethane equivalents. This makes it easier for the reader to analyze the results than to look at a table with a lot more small different emissions. However, the two last projects and sum the total emissions from the consumables to environmental impact categories corresponding to environmental problems. The impact categories used is GWP (green house potential) and AP (acid potential). This approach is easier to communicate than some chemical product name.

\subsection{End of life}

Only one project had a holistic with of the can lifecycle. The steel can project used LCI data that considered steel made from $80 \%$ recycled material, which is the world's total average (updated 2007) (ELCD 2012). For a project with the purpose to label the product with environmental impact it is convenient to use a holistic life cycle view. 
Andersson, Skoogh and Johansson

Table 1 Comparing the six cases

\begin{tabular}{|c|c|c|c|c|c|c|}
\hline & Apple juices & Sausages & Dairy products & Automobile parts & Fork lifter part & Steel can \\
\hline Goals and scope & $\begin{array}{l}\text { Create a model } \\
\text { for analyses }\end{array}$ & $\begin{array}{l}\text { Create a model } \\
\text { for analyses }\end{array}$ & $\begin{array}{l}\text { Create a model } \\
\text { for analyses }\end{array}$ & $\begin{array}{c}\text { Create a model to } \\
\text { evaluate invest- } \\
\text { ments }\end{array}$ & $\begin{array}{l}\text { Create a model } \\
\text { and propose a } \\
\text { method. }\end{array}$ & $\begin{array}{l}\text { Label a product } \\
\text { with GWP }\end{array}$ \\
\hline $\begin{array}{c}\text { Used Impact Cat- } \\
\text { egories }\end{array}$ & No & Energy & $\begin{array}{l}\mathrm{CO} 2, \mathrm{SO} 2, \mathrm{NO} 3 \\
\text { and ethane ekv }\end{array}$ & Energy & GWP, AP & GWP \\
\hline $\begin{array}{l}\text { Layers of Aggre- } \\
\text { gated equations }\end{array}$ & Yes & Yes & Yes & Yes & Yes & Yes \\
\hline Functional Unit & The Product & The Product & $\begin{array}{l}\text { Total process, } \\
\text { allocated later to } \\
\text { product }\end{array}$ & The total Process & The product & The Product \\
\hline Variants & Few & Few & Many & Few & One & Many, but similar \\
\hline Validating & $\begin{array}{l}\text { Historical, pro- } \\
\text { cess and waste }\end{array}$ & $\begin{array}{l}\text { Validated process } \\
\text { model }\end{array}$ & $\begin{array}{l}\text { Process data is } \\
\text { validated to his- } \\
\text { tory }\end{array}$ & & $\begin{array}{l}\text { Historical process } \\
\text { data }\end{array}$ & $\begin{array}{c}\text { Historical process } \\
\text { data }\end{array}$ \\
\hline $\begin{array}{l}\text { Waste considera- } \\
\text { tions }\end{array}$ & $\begin{array}{l}\text { All wasted prod- } \\
\text { ucts is allocated } \\
\text { to the other prod- } \\
\text { ucts }\end{array}$ & $\begin{array}{l}\text { Multiple products } \\
\text { on allocated } \\
\text { wasted material }\end{array}$ & No, included & $\begin{array}{l}\text { Nothing consid- } \\
\text { ered }\end{array}$ & & $\begin{array}{l}\text { Recycling loops } \\
\text { included in LCI } \\
\text { data. }\end{array}$ \\
\hline Model Usage & $\begin{array}{l}\text { Model and sce- } \\
\text { narios }\end{array}$ & Scenarios & $\begin{array}{c}\text { Provide a model, } \\
\text { need better data }\end{array}$ & $\begin{array}{c}\text { Investment sce- } \\
\text { narios }\end{array}$ & Only Internal & Eco-labeling \\
\hline Method & $\begin{array}{l}\text { Extended Banks } \\
\text { methodology }\end{array}$ & REELIV & REELIV & SIMTER Tool & New & $\begin{array}{l}\text { Refined from } \\
\text { previous }\end{array}$ \\
\hline $\begin{array}{l}\text { Process electrici- } \\
\text { ty measurements }\end{array}$ & Yes & No & Yes & No & Yes & Yes \\
\hline
\end{tabular}

\section{DISCUSSION}

Based on the results and the experiences from the six case studies (section 4), there is a need for a standardized method with best practice descriptions and guidelines. Many times, the cases have had to reinvent their work procedure and there has been lots of focus on model building resulting in insufficient efforts to focus on answering the question. Furthermore, the lack of solid descriptions leads to inconsistent results and, thus, difficulties in comparing scenarios, products, and production processes with each other. Therefore, this paper provides a basis for such a standardized method. Based on the collected experiences, most stages in a project would benefit of guideline and framework with a set of possibilities.

Data management was problematic in all the reviewed cases studies. Beside the extensive input data collection for the conventional simulation model, there is a need to find information of consumable consumption, i.e. energy, auxiliary media, raw material and waste data. For these consumables there is also a need to find rigid LCI information, which makes the data management procedure very extensive. During the most recent case study an idea of a pre-data study, before any conceptual model is created, was launched. In this phase only easily accessible data are identified. The conceptual model can then be created based on the information gained from the pre-data study, avoiding difficult modeling in terms of data collection.

To support the verification process of the environmental output, it is important to separate emission data from the consumables and process data that the emission results are based on. One option is to calculate emissions based on used consumables and base the use of consumable on process times, and to do this in a database or spread-sheet after the simulation is executed. Then the data can easily be verified on each level avoiding inherent errors. 


\section{Andersson, Skoogh and Johansson}

For internal validation, one can use sensitivity analyses on the output data to get better prioritization strategies deciding what input information is most significant. The most important input data require more extensive data collection and data with higher quality. The most significant information can be conventional process data, consumable consumption or environmental LCI data.

Validation for the LCA studies in general is preformed through an external review process. To be able to trustfully use the results from a LCA in a DES approach, an external review is hard to avoid. There is a high dependence on the collected data, used LCI data sets, and system boundaries.

Only two of the studied cases considered overheads such as the emissions of facilities and supporting functions. The allocation to other products using the same resources should (according to ISO 14040) primarily be based on system integration, which in many cases is very time consuming, secondly be based on physical factors as used space, weight, or volume. The final option is to base the allocation on economic factors. For facilities the physical space used for the product compared to other can be used. This approach was used in both the fork lift case and the steel can case. In the fork lift case, other allocation approaches was evaluated and discussed. The results proved a big difference between allocation methods and it is therefore important to choose a method that represent the why the shared resources exist or is using more consumables, i.e. energy. This problem further exemplifies the importance of clear guidelines to enable a standardized work procedure and, thus, consistent analysis results.

This paper analyzes and compares six case studies, all with connection to the affiliation of the authors. Including other cases could result in different experiences. However, the contact persons for all cases are available for the authors, enabling interviews and better background information of the cases.

This paper promotes any research of tools or standardized methods to be used in a combined approach of DES and LCA. There is a need to support the simulation modeler with a standardized method covering all steps of a project (e.g. system delimitations, model building, data sources and analysis, and communication of analysis results) when combining two such different areas as LCA and DES. Given further development on increased efficiency and standardization, there is substantial potential in using DES models with LCA data for improvement of sustainability performance in production systems as well as for ecolabeling and benchmarking of products, both for manufacturing companies and end users.

\section{CONCLUSION}

This paper has provided a list of experiences from projects combining LCA and DES. From the experiences and diverse methods used in the cases it is clear that a standardized methodology is needed. The application of DES for sustainability analyses has been developed during the latest decade and there is now enough documented information to provide useful recommendations for further research. A review of six real-world case studies resulted in a list of advices and experiences focusing on the project set-up, methodological choices, and data management problems. The most frequently mentioned experiences and problem areas are (see Section 4 for further details):

- Vague problem formulation resulting in unnecessarily extensive and expensive models not answering the correct question.

- Non-standardized verification and validation procedures resulting in unreliable results inappropriate for comparisons and benchmarking.

- Data management is expensive, showing the importance of well-structured and limitative methods.

The six investigated cases studies are extracted from three more comprehensive research projects on combining DES and LCA and put on a timeline showing how the research objectives have evolved over time. The first project focused on methodological development, the second project on software development, and the third on standardizing the work-procedures and performance indicators in order to increase efficiency and enable benchmarking. This timeline shows that initial experiences from model and software development have, during the latest years, been replaced with concerns about the application of various allocation strategies for overhead costs and other more mature problems. Together the three projects 


\section{Andersson, Skoogh and Johansson}

provide a holistic view of how to perform a LCA analyst in DES and the six cases studies show that it is feasible, and yet promising, to perform detailed sustainability analyses within DES.

The result will be used for method development and as input for special tool development. The tool development started in a previous article by Andersson et al. (2012).

\section{ACKNOWLEDGEMENTS}

The researchers would like to acknowledge all the authors and modelers of the studied cases.

The funding for this research is granted by ProViking through the EcoProIT project.

This work has been carried out within the Sustainable Production Initiative and the Production Area of Advance at Chalmers University of Technology, which is gratefully acknowledged.

\section{REFERENCES}

Alvemark, O. \& F. Persson. 2007. "Flödessimulering av livsmedelsproduktion; syrade mejeriprodukter". Institutionen för produkt- och produktionsutveckling, Produktionssystem, Chalmers tekniska högskola.

Andersson, J., B. Johansson, J. Berglund \& A. Skoogh 2012. "Framework for Ecolabeling using Discrete Event Simulation" In: Proceedings of the 2012 Spring Simulation Multiconference

Andersson, J., A. Skoogh \& B. Johansson 2011. "Environmental Activity Based Cost using Discrete Event Simulation" In: Proceedings of the 2011 Winter Simulation Conference Edited by: S. Jain, R. R. C., J. Himmelspach, K.P. White, and M. Fu.

Banks, J. \& B. L. Nelson 2010. Discrete-event system simulation, Prentice Hall.

ELCD 2012. "European Reference Life Cycle Database" http://lca.jrc.ec.europa.eu/lcainfohub/datasetArea.vm

Ingvarsson, A. \& C. Johansson. 2006. "Flödessimulering av livsmedelsproduktion; Ingemar Johansson $i$ Sverige $A B^{\prime \prime}$. Institutionen för produkt- och produktionsutveckling, Produktionssystem, Chalmers tekniska högskola.

ISO - International Organization for Standardization 2006a. "ISO 14040:2006b Environmental management -- Life cycle assessment -- Principles and framework" Geneva

ISO - International Organization for Standardization 2006b. "ISO 14044:2006c Environmental management -- Life cycle assessment -- Requirements and guidelines" Geneva

Lind, S., B. Johansson, J. Stahre, C. Berlin, Å. Fasth, J. Heilala, K. Helin, S. Kiviranta, B. Krassi, J. Montonen, H. Tonteri, S. Vatanen \& J. Viitaniemi. 2009. "SIMTER - A Joint Simulation Tool for Production Development".

Lind, S., B. Krassi, B. Johansson, J. Viitaniemi, J. Heilala, J. Stahre, S. Vatanen, Å. Fasth \& C. Berlin 2008. "SIMTER: A Production Simulation Tool for Joint Assessment of Ergonomics, Level of Automation and Environmental Impacts." In: The 18th International Conference on Flexible Automation and Intelligent Manufacturing

Lindskog, E., L. Lundh, J. Berglund, Y. T. Lee, A. Skoogh \& B. Johansson 2011. "A Method for Determing the Environmental Footprint of Industrial Products using Simulation" In: Proceedings of the 2011 Winter Simulation Conference Edited by: S. Jain, R. R. C., J. Himmelspach, K.P. White, and M. Fu

Löfgren, B. \& A.-M. Tillman 2011. "Relating manufacturing system configuration to life-cycle environmental performance: discrete-event simulation supplemented with LCA" Journal of Cleaner Production, 19, 2015-2024.

Persson, D. \& J. Karlsson. 2007. "Flödessimulering av livsmedelsproduktion; Kiviks Musteri AB - En studie inom forskningsprojektet REELIV". Institutionen för produkt- och produktionsutveckling, Produktionssystem, Chalmers tekniska högskola.

Sargent, R. G. Verification and validation of simulation models. In: Simulation Conference (WSC), Proceedings of the 2010 Winter, 5-8 Dec. 2010 2010. 166-183. 
Seow, Y. \& S. Rahimifard 2011. "A framework for modelling energy consumption within manufacturing systems" CIRP Journal of Manufacturing Science and Technology, 4, 258-264.

Skoogh, A., B. Johansson \& H. Lars 2011. "Data Requirements and Representation for Simulation of Energy Consumption in Production Systems" In: In Proceedings of the 44th CIRP Conference on Manufacturing Systems

Solding, P., D. Petku \& N. Mardan 2009. "Using simulation for more sustainable production systems methodologies and case studies" International Journal of Sustainable Engineering, 2, 111-122.

Thiede, S., C. Herrmann \& S. Kara 2011. "State of Research and an innovative Approach for simulating Energy Flows of Manufacturing Systems" In: Glocalized Solutions for Sustainability in Manufacturing CIRP Braunschweig

\section{AUTHOR BIOGRAPHIES}

JON ANDERSSON is a PhD student at Chalmers University of Technology. He works mainly in the field of production simulation and especially in a project called EcoProIT (http://www.ecoproit.com). The project aims to build an industrial tool for environmental impact analysis in a powerful DES environment. His email address is Jon.Andersson@chalmers.se.

ANDERS SKOOGH is a researcher and lecturer in the area of Virtual Production at the Department of Product and Production Development, Chalmers University of Technology, Sweden. He received the degree of Licentiate of Engineering in 2009 and his $\mathrm{PhD}$ in Production Systems in 2011, both from Chalmers. Before starting his research career, he accumulated industrial experience from an employment as a logistics developer at Volvo Car Corporation. His main research area is virtual tools for decision support in development of sustainable production systems. The current focus is on efficient input data management in simulation of production flows, for example by developing and evaluating methodologies for automated data processing. His email address is Anders.Skoogh@chalmers.se.

BJÖRN JOHANSSON is Associate Professor and vice head of Production Systems division at the Department of Product and Production Development, Chalmers University of Technology, Sweden. He serves as Production Modeling Corporation director for the European office in Gothenburg. His research interest is in the area of discrete-event simulation applied for manufacturing industries, including environmental effects modeling, modular modeling methodologies, software development, user interfaces, and input data architectures. His email address is Bjorn.Johansson@chalmers.se. 